\title{
ANSIEDADE EM BAILARINOS PROFISSIONAIS NAS APRESENTAÇÕES DE DANÇA
}

\author{
Ana Carolina Silva Constantino, Universidade de Pernambuco - UPe - Pernambuco - Brasil \\ Wagner Luiz Prado, Universidade de Pernambuco - UPe - Pernambuco - Brasil \\ Mara Cristina Lofrano-Prado, Universidade Federal de Pernambuco - UFPe - Pernanbuco - Brasil
}

\section{RESUMO}

Introdução: A ansiedade é um estado emocional que pode influenciar de maneira significativa o desempenho de atletas em competições e de bailarinos nas apresentações de dança. $\mathrm{O}$ estudo objetivou identificar o nível de ansiedade em bailarinos profissionais antes e após apresentações, e verificar suas possíveis relações com gênero, idade e tempo de experiência. Materiais e Métodos: A amostra foi composta por 21 bailarinos profissionais de ambos os gêneros com uma média de idade

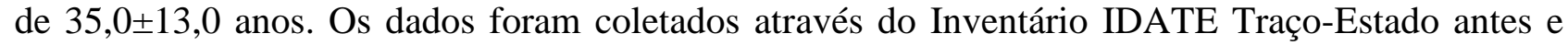
após apresentações. Resultados: Os resultados revelaram a presença de maiores níveis de ansiedade antes do evento do que após as apresentações tanto para a ansiedade traço como para a ansiedade estado. Nenhuma relação foi encontrada entre nível de ansiedade, gênero, idade e tempo de experiência com a dança. Discussão: Desta forma, podemos concluir que o espetáculo de dança é um fator desencadeante para o aumento da ansiedade. É necessário mais estudos sobre a influência da ansiedade no desempenho de bailarinos, para que mais discussões sejam realizadas e analisadas visando assim, um melhor desempenho em palco.

Palavras-Chave: Ansiedade; Desempenho atlético; Dança.

\section{ANXIETY IN PROFESSIONAL DANCERS IN DANCE PERFORMANCES}

\begin{abstract}
Introduction: Anxiety is an emotional state that may significantly influence the performance of athletes in competitions and the dancers dance performances. The study aimed to identify the level of anxiety in professional dancers before and after performances, and verify their possible relationships with gender, age and length of experience. Materials and Methods: The sample consisted of 21 professional dancers of both genders with a mean age of $35.0 \pm 13.0$ years. Data were collected through the State-Trait Inventory STAI before and after performances. Results: The results revealed the presence of higher levels of anxiety before the event than after the presentations for both anxiety and trait anxiety for the state. No relationship was found between anxiety level, gender, age and years of experience with dance. Discussion: Thus, we conclude that the dance is a trigger for increased anxiety. It is necessary more studies about the influence of anxiety on performance of dancers, so that more discussions are conducted and analyzed in order to thus perform better on stage.
\end{abstract}

KEY-WORDS: Anxiety; Athletic performance; Dancing. 


\section{INTRODUÇÃO}

Ansiedade é um estado emocional que pode influenciar de maneira significativa o desempenho de atletas em competições. É caracterizada por tensão, apreensão, preocupação, nervosismo, e pode estar relacionada com a ativação do corpo. ${ }^{1}$ A ansiedade possui duas dimensões, a ansiedade-traço e ansiedade-estado. ${ }^{2,3,4}$ A primeira está relacionada à personalidade, é uma característica permanente, ou seja, o indivíduo tem uma predisposição em perceber situações de ameaça. Já a segunda é um componente em constante variação, que depende das circunstâncias, e é caracterizada pelo sentimento de medo e tensão associado com a ativação do sistema nervoso autônomo. ${ }^{5}$

A ansiedade competitiva é um dos fatores psicológicos que influenciam de maneira significativa o rendimento esportivo. ${ }^{3,6,7,8}$ Atletas com altos níveis de ansiedade podem apresentar dificuldades na coordenação, falta de concentração, maior dispêndio energético e até mesmo um estreitamento do campo de atenção, ${ }^{1}$ situação esta que também afeta bailarinos em pré-estréias ou em grandes apresentações de dança. ${ }^{9}$

A dança é vista, muitas vezes, apenas como uma atividade lúdica, mas vale salientar que ela abrange um universo de tensões, de necessidade de aperfeiçoamento técnico e de perfeccionismo, ${ }^{10}$ ou seja, as pressões psicológicas sofridas por atletas de alto rendimento, também estão presentes no mundo da dança. Assim, o bailarino vivencia características de um desempenho atlético, ou seja, com grande exigência física e mental, em que o estresse e a ansiedade pré-competitiva podem estar presentes na competição do bailarino com o seu próprio corpo. ${ }^{10,11}$

Fatores como o medo de errar, esquecer a seqüência coreográfica, a presença da platéia, devem ser levados em consideração antes das apresentações, visto que podem influenciar de maneira negativa o desempenho físico e psicológico do bailarino. ${ }^{9}$

Entretanto, até o presente momento, são poucos os estudos que se preocuparam em abordar tal questão, essencial para os diversos profissionais envolvidos com a dança. A partir disso, este estudo tem como objetivo identificar os níveis de ansiedade em bailarinos profissionais antes e após as apresentações de dança, bem como correlacionar o nível dessa ansiedade com o gênero, idade e tempo de experiência. 


\title{
MATERIAIS E MÉTODOS
}

\author{
Modelo do estudo
}

A pesquisa caracteriza-se por ser quantitativa, empírico-analítica e transversal. Após receberem todas as informações quanto aos objetivos da pesquisa, todos os voluntários assinaram o termo de consentimento livre e esclarecido. O presente estudo atendeu às determinações éticas que envolvem seres humanos e não apresentou conflitos de interesses, sendo previamente aprovado pelo Comitê de Ética em Pesquisa da Universidade de Pernambuco (Projeto no 198/09).

\section{População e Amostra}

A amostra foi composta por 21 voluntários sendo, 17 do gênero feminino (80,95\%) com média de

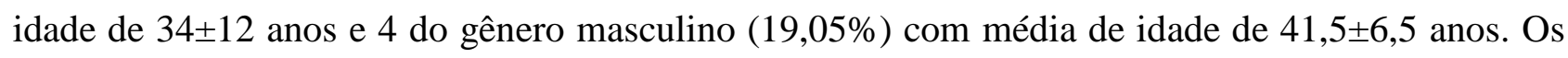
voluntários foram convidados a participar do estudo nas apresentações do $14^{\circ}$ Festival Internacional de Dança do Recife, na cidade de Recife-PE.

Foram utilizados como critérios de inclusão: faixa etária acima de 18 anos de idade e ter participado de pelo menos uma apresentação de dança profissional. Foram excluídos da amostra, bailarinos que fizessem uso de substâncias ansiolíticas e/ou ansiogênicas, que possuíam algum transtorno psiquiátrico e/ou que estivessem sob tratamento psiquiátrico.

\section{Instrumentos}

Os sintomas de ansiedade foram avaliados por meio do Inventário de Ansiedade Traço-Estado (IDATE). ${ }^{12,13} \mathrm{Na}$ escala Idate Estado o participante descreve como ele se sente "agora, neste momento" através de 20 itens abordados em uma escala do tipo Likert de 4 pontos:

1- absolutamente não;

2- um pouco;

3- bastante;

4- muitíssimo.

Já na escala Idate Traço o participante descreve como ele "geralmente se sente", também composta 
por 20 itens apresentados em uma escala do tipo Likert de 4 pontos:

1- quase nunca;

2- ás vezes;

3- freqüentemente;

4- quase sempre.

Além do questionário, foi realizada, previamente, uma entrevista estruturada para obter informações relevantes ao estudo, como idade e tempo de experiência com a dança. Antes da aplicação do questionário foi perguntado verbalmente a cada participante se este estava sob o uso de substâncias ansiolíticas e/ou ansiogênicas, ou se estavam sob tratamento psiquiátrico e/ou possuíam algum transtorno psiquiátrico.

A aplicação do questionário IDATE traço-estado ocorreu em dois momentos distintos: aproximadamente 30 minutos antes da apresentação e imediatamente após.

Todas as avaliações foram realizadas em uma sala silenciosa, respeitando-se todas as orientações de aplicação do instrumento, e por um profissional capacitado.

\section{Análise estatística}

Os dados foram analisados através do programa Statistica versão 6.1. Inicialmente foi realizado um teste de normalidade dos dados utilizando o teste Komolgorov-Smirnov. Para comparação entre o escores de ansiedade pré e pós, foi utilizado o test T de Student. As correlações foram efetuadas através da correlação de Pearson. O nível de significância foi fixado em $\mathrm{p} \leq 0,05$.

\section{RESULTADOS}

Antes das apresentações 80,95\% dos bailarinos apresentaram nível médio de ansiedade estado, de acordo com a classificação do Idate-Estado, com escores entre 31 e 49 pontos e 19,05\% da amostra apresentaram nível baixo de ansiedade estado, com a obtenção entre 0 a 30 pontos (Figura 1). Em 
relação ao nível de ansiedade traço antes das apresentações, 80,95\% dos participantes apresentaram nível médio, 9,52\% apresentaram nível baixo e 9,52\% apresentaram nível alto de ansiedade.

\section{Figura 1 Níveis de ansiedade pré-apresentação} de dança

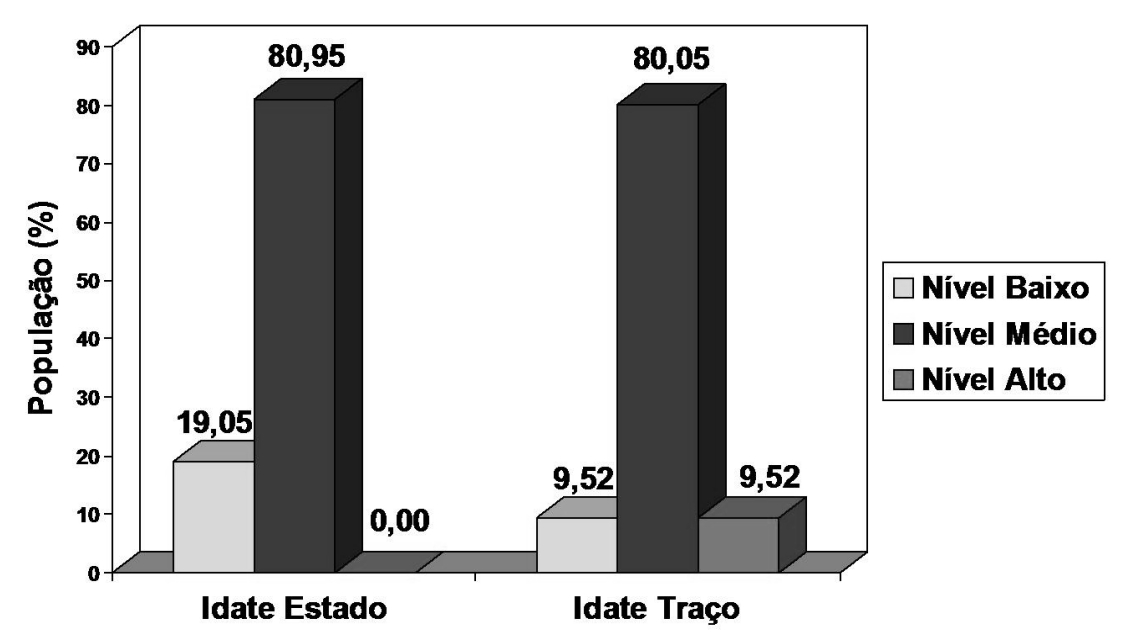

Após as apresentações os resultados encontrados mostraram que 66,66\% dos bailarinos apresentaram nível médio, e 33,33\% apresentaram nível baixo de ansiedade estado. Em relação a ansiedade traço após as apresentações de dança, 76,19\% dos bailarinos apresentaram nível médio e 23,80\% apresentaram nível baixo de ansiedade traço (Figura 2).

Figura 2 Níveis de ansiedade pós-apresentação de dança

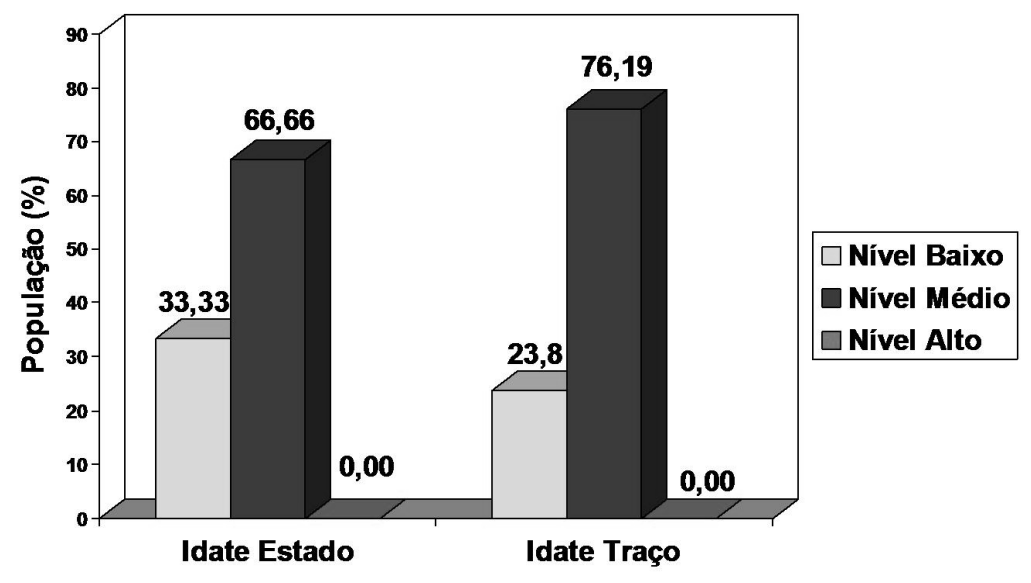


A tabela 1 mostra os valores médios e o desvio padrão dos escores de ansiedade traço e estado antes e após as apresentações de dança.

Tabela 1: Comparação entre os escores de ansiedade estado e traço antes e após as apresentações de dança

\begin{tabular}{cccc}
\hline & Pré apresentação & Pós apresentação & p \\
\hline Idate estado & $37,61 \pm 5,88$ & $32,42 \pm 6,21$ & 0,008 \\
Idate traço & $37,85 \pm 7,09$ & $34,66 \pm 6,27$ & 0,001 \\
\hline
\end{tabular}

Verificou-se que a média de escore do Idate Estado e do Idate Traço atingida pelos bailarinos antes das apresentações foi maior do que a média de escore do Idate Estado e Idate Traço atingida após as apresentações de dança, observando-se que os bailarinos apresentaram maiores níveis de ansiedade antes das apresentações do que após as mesmas.

\section{DISCUSSÃO}

É através do jogo que o atleta demonstra suas habilidades, ou seja, o jogo é o momento em que ele prova ser ou não mais competente. Tendo esse pressuposto, o bailarino tem a apresentação como o meio de demonstrar suas habilidades tanto artísticas como técnicas. ${ }^{14}$ Podendo vivenciar a vitória ou o fracasso e a frustração. ${ }^{10}$ Essas situações acabam por desencadear a ansiedade, aumentando assim a pressão sobre o desempenho e dificultando a realização de atividades. ${ }^{15}$

No presente estudo, os bailarinos antes das apresentações de dança indicaram a presença de níveis de ansiedade, ou seja, apesar da dança não ser um esporte de alto rendimento ela pode desencadear sintomas de ansiedade nas apresentações. Esses dados corroboram com estudo em que autores ao investigarem o nível de estresse e ansiedade em bailarinos e bailarinas profissionais na pré-estréia de um espetáculo de dança, encontraram sintomas bem definidos que significaram a presença de estresse e ansiedade nas apresentações. ${ }^{9}$ 
Antes das apresentações de dança foi constatado um nível médio de ansiedade nos bailarinos, o que pode ser um resultado positivo. Visto que apresentar um nível moderado de ansiedade antes de uma apresentação pode ser benéfico no seu desempenho. Antes e durante uma competição é necessário um estado mínimo de disposição para competir chamada de ativação. ${ }^{16}$ De acordo com a hipótese do U invertido um ótimo desempenho está relacionado com o nível ideal de ativação e um mau desempenho está relacionado à ativações baixas ou muito altas, ou seja, à medida que há um aumento na ativação ou ansiedade, há uma melhora no desempenho, até um ponto ideal em que ocorre o rendimento esperado, caso haja aumentos adicionais na ativação o desempenho tende a declinar. ${ }^{17,1,4}$

Em relação ás diferenças do nível de ansiedade entre os gêneros, muitos estudos apontam o gênero feminino com maior nível de ansiedade do que o gênero masculino. ${ }^{18,19,20,21}$ Segundo esses autores esse aspecto pode estar atribuído ao fato da competição ser mais enfatizada para o gênero masculino do que para o feminino, além do fato da mulher sentir maior pressão e ser mais cobrada do que os homens. Embora estudos afirmem essa associação do nível de ansiedade com o gênero, não foi possível constatar isso no presente estudo, pois não houve diferença significativa nos dados coletados.

Ao associar as variáveis de idade e do tempo de experiência na dança com o nível de ansiedade, também não houve diferenças significativas. Do mesmo modo, num estudo com 105 atletas paraibanos de diversas modalidades esportivas, os autores não encontraram essa associação da idade e do tempo de experiência com o nível de ansiedade. ${ }^{21}$ Esses resultados não corroboram com outros estudos que atribuem ao atleta mais jovem ${ }^{5,6}$ e atletas com menos experiência um maior nível de ansiedade. ${ }^{22,20,23}$

\section{CONCLUSÃO}

A presente pesquisa procurou estudar a presença de níveis de ansiedade em bailarinos profissionais nas apresentações de dança, bem como a associação do nível de ansiedade com as variáveis de gênero, faixa etária e tempo de experiência. Assim, os resultados mostraram a presença de nível médio de ansiedade nos bailarinos antes das apresentações, constatando maiores níveis de ansiedade 
antes do que após as apresentações. Esses achados são de extrema importância uma vez que revelam que as apresentações de dança podem ser consideradas como um agente estressor para os dançarinos, mostrando a importância de intervenções psicológicas que visem auxiliá-los a controlar a ansiedade, e desta forma melhorar a performance de dançarinos profissionais. O presente estudo apresenta como limitação a dificuldade em aplicar o questionário utilizado em poucos minutos antes e depois da apresentação, momentos estes de maiores tensões. Desta forma, é necessária a realização de mais estudos para aprofundar as discussões que acometem a ansiedade e sua influência no desempenho dos bailarinos.

Por fim, ressalta-se a importância de estudos sobre o nível de ansiedade e o desempenho atlético no campo esportivo e principalmente na dança, devido a escassez destes na área da psicologia do esporte para que maiores discussões sejam aprofundadas e analisadas afim de contribuir na intervenção do profissional em amenizar a interferência psicológica no desempenho do bailarino.

\section{REFERÊNCIAS}

${ }^{1}$ WEINBERG, R.S.; GOULD, D. Fundamentos da psicologia do esporte e do exercício. 2. ed. Porto Alegre: Artmed, 2001.

${ }^{2}$ UCHA, F. G. et al. Ansiedad e indicadores de rendimiento em deportistas. Lecturas: Educación Física y Deportes, 2001; 33. Disponível em: http://www.efdeportes.com/efd33a/ansied.htm.

${ }^{3}$ PUJALS, C.; VIEIRA, L. F. Análise dos fatores psicológicos que interferem no comportamento dos atletas de futebol de campo. Revista de Educação Física, v. 13, n. 1, p. 89-97, 2002.

${ }^{4}$ SAMULSKI, D. Psicologia do esporte: manual para a educação física, psicologia e fisioterapia. São Paulo: Manole, 2002.

${ }^{5}$ DE ROSE JR, D.; VASCONCELLOS, E. G. Ansiedade-traço competitiva e atletismo: um estudo com atletas infanto-juvenis. Revista Paulista de Educação Física, v. 11, n. 2, p. 148-154, 1997.

${ }^{6}$ DETANICO, D.; SANTOS, S. G. Variáveis influenciando e sendo influenciadas pela ansiedade- 
traço pré-competitiva: um estudo com judocas. Lecturas: Educación Física y Deportes, 2005. Disponível em: http://www.efdeportes.com/efd90/judocas.htm.

${ }^{7}$ BERTUOL, L.; VALENTINI, N. C. Ansiedade competitiva de adolescentes: gênero, maturação, nível de experiência e modalidades esportivas. Revista de Educação Física, v. 17, n. 1, p. 65-74, 2006.

${ }^{8}$ LAVOURA, T. N.; BOTURA, H. M. L.; MACHADO, A. A. Estudo da ansiedade e as diferenças entre gêneros em um esporte de aventura competitivo. Refeld, v. 1, n. 3, p. 74-81, 2006.

${ }^{9}$ SOUSA, F. N. G.; MARIANI, M. E., SAMULSKI, D. M. Análise do nível de estresse e da ansiedade em bailarinos e bailarinas profissionais na pré-estréia de um espetáculo de dança. 68f. 2002. Dissertação (Mestrado) - Universidade Católica de Brasília, Brasília, 2002.

${ }^{10}$ ASSIS, M.; CORREIA, A. M. Entre o jogo estético e o impulso lúdico: um ensaio de dança. Revista Brasileira de Ciências do Esporte, v. 27, n. 2, p. 121-130, 2006.

${ }^{11}$ GUIMARÃES, A. C.A.; SIMAS, J. P. N. Lesões no ballet clássico. Revista de Educação Física, v. 12, n. 2, p. 89-96, 2001.

${ }^{12}$ SPIELBERGER, C. D.; GORSUCH, R. L.; LUSHENE, E. Manual for the State-Trait Anxiety Inventory (“Self - Evalution Questionaire”). Palo Alto, CA Consulting Psychologist, 1970.

${ }^{13}$ BIAGGIO, A. M. B. Ansiedade, raiva e depressão na concepção de C.D. Spielbeger. Revista de Psiquiatria Clínica, v. 25, n. 6, 1999.

${ }^{14}$ DE ROSE JR., D. et al. Situações de Jogo como fonte de "stress" em modalidades esportivas coletivas. Revista Brasileira de Ciências do Esporte, v. 18, n. 4, p. 385-95, 2004.

${ }^{15}$ TAJET-FOXELL, B. The stress factor. In: DYKE, S. The dancers' survival guide: essential information for students, dancers, teachers and coreographers. London: Dance UK, 1999. 
${ }^{16}$ RUBIO, K. A psicologia do esporte: histórico e áreas de atuação e pesquisa. Psicologia Ciência e Profissão, v.19, n. 3, p. 60-69, 1999.

${ }^{17}$ MORAES, L. C. Ansiedade e desempenho no esporte. Revista Brasileira de Ciência e Movimento, v. 4, n. 2, p. 51-56, 1990.

${ }^{18}$ LA ROSA, J. Ansiedade, sexo, nível sócio-econômico e ordem de nascimento. Psicologia Reflexão e Crítica, v. 11, n. 1, 1998.

${ }^{19}$ MARTINS, J. P.; LOPES JR., P. F.; ASSUMPÇÃO, R. A. B. Ansiedade-estado competitiva e basquetebol: um estudo comparativo com atletas do sexo feminino e masculino. Arquivos de Ciências da Saúde UNIPAR, v. 8, n. 2, p. 107-110, 2004.

${ }^{20}$ DIAS, C. S. L. Do stress e ansiedade às emoções no desporto: da importância da sua compreensão à necessidade da sua gestão. 2005. Tese (Doutorado) - Universidade do Minho, Portugal, 2005.

${ }^{21}$ GONÇALVES, M. P.; BELO, R. P. Ansiedade-traço competitiva: diferenças quanto ao gênero, faixa etária, experiência em competições e modalidade esportiva em jovens atletas. Revista Semestral da Área de Psicologia da Universidade São Francisco, v. 12, n. 2, p. 301-307,2007. Disponível em: http://pepsic.bvspsi.org.br/scielo.php?script=sci_arttext\&pid=S141382712007000200018\&lng=pt\&nrm=iso.

${ }^{22}$ MANOEL, C. L. L. Ansiedade competitiva entre sexos: uma análise de suas dimensões e seus antecedentes. Revista Paulista de Educação Física, v. 8, n. 2, p.36-53, 1994.

${ }^{23}$ LAVOURA, T. N.; MACHADO, A. A. Esporte de aventura de rendimento e estados emocionais: relações entre ansiedade, autoconfiança e auto-eficácia. Motriz, v. 12, n. 2, p. 143-148, 2006. 